\title{
Acute vascular responses to the frequency of vibration transmitted to the hand
}

\author{
Massimo Bovenzi, Christopher J Lindsell, Michael J Griffin
}

\begin{abstract}
Objectives-To investigate the acute effects of the frequency of hand transmitted vibration on finger circulation. A further aim was to investigate whether the frequency weighting assumed in current standards for hand transmitted vibration reflects the haemodynamic changes which occur in the fingers exposed to vibration with different frequencies but with the same frequency weighted acceleration magnitude.

Methods-Finger skin temperature (FST) and finger blood flow (FBF) were measured in the middle fingers of both hands of 10 healthy men. With a static load of $10 \mathrm{~N}$, the right hand was exposed for 15 minutes to the following root mean square (rms) acceleration magnitudes and frequencies of vertical vibration: $5.5 \mathrm{~m} / \mathrm{s}^{2}$ at $16 \mathrm{~Hz} ; 11 \mathrm{~m} / \mathrm{s}^{2}$ at $31.5 \mathrm{~Hz} ; 22 \mathrm{~m} / \mathrm{s}^{2}$ at $63 \mathrm{~Hz}$; $44 \mathrm{~m} / \mathrm{s}^{2}$ at $125 \mathrm{~Hz}$; and $88 \mathrm{~m} / \mathrm{s}^{2}$ at $250 \mathrm{~Hz}$. These exposures to vibration produce the same frequency weighted acceleration magnitude $\left(5.5 \mathrm{~m} / \mathrm{s}^{2} \mathrm{rms}\right)$ according to the frequency weighting included in the international standard ISO 5349. A control condition consisted of exposure to the static load only. Finger circulation was measured before application of the vibration and static load and at fixed intervals during exposure to vibration and a 45 minute recovery period.
\end{abstract}

Results-No significant changes in finger circulation were found with only the static load. The FST did not change significantly during or after acute exposure to vibration. In the vibrated right finger, exposures to vibration with frequencies of $31.5-250 \mathrm{~Hz}$ provoked a greater reduction in FBF than did vibration of $16 \mathrm{~Hz}$ or the static load only. In the non-vibrated left finger, the FBF measured with vibration at each frequency of $63-250 \mathrm{~Hz}$ was significantly lower than that measured with static load only. The reduction in FBF during exposure to vibration with any frequency was stronger in the vibrated finger than in the non-vibrated finger. In both fingers, there was a progressive decrease in FBF after the end of exposure to vibration with frequencies of $31.5-250$ Hz. The higher the frequency of vibration, the stronger the decrease in FBF in both fingers during recovery.

Conclusions-Acute exposures to vibration with equal frequency weighted magnitude reduce the $F B F$ in both vibrated and non-vibrated fingers for frequencies between 31.5 and $250 \mathrm{~Hz}$. The extent of digital vasoconstriction after exposure to vibration increases with increasing frequency. The frequency weighting given in current standards tends to overestimate the vasoconstriction associated with acute exposures to vibration frequencies around $16 \mathrm{~Hz}$.

(Occup Environ Med 2000;57:422-430)

Keywords: finger circulation; frequency weighted acceleration magnitude; vibration frequency

The vasoconstrictor effects of hand transmitted vibration in the fingers of workers who use vibrating tools are thought to depend to a great extent on the frequency, magnitude, and duration of the vibration stimulus. ${ }^{1}$ In previous experimental studies, we found that finger blood flow (FBF) was inversely related to the root mean square (rms) acceleration magnitude and the duration of $125 \mathrm{~Hz}$ hand transmitted vibration: the greater the acceleration magnitude of vibration and the longer the duration of exposure, the stronger the reduction of FBF in both an ipsilateral and a contralateral finger during and after exposure to vibration. ${ }^{23}$

Current standards for hand transmitted vibration assume that the sensitivity of the hand-arm system to vibration acceleration is independent of the vibration frequency below $16 \mathrm{~Hz}$ but reduces in inverse proportion to the vibration frequency at higher frequencies. ${ }^{4}{ }^{5}$ As a result, the international standard ISO 5349 advocates that vibration acceleration should be weighted by a frequency weighting curve which has a slope of $0 \mathrm{~dB}$ below $16 \mathrm{~Hz}$ and $-6 \mathrm{~dB}$ per octave above $16 \mathrm{~Hz}^{4}{ }^{4}$ By contrast with these assumptions, some laboratory experimental studies have shown that vibration frequencies above $30 \mathrm{~Hz}$ induce greater vasoconstrictor effects than lower frequencies, in both animal preparations and human fingers. ${ }^{67}$

The aim of this investigation was to study the dependence of acute vascular effects on the frequency of vibration transmitted to the hand. Also, it was designed to investigate whether the frequency weighting assumed in current standards reflects the haemodynamic changes found in the fingers exposed to different vibration stimuli with the same frequency weighted rms acceleration magnitude.

Subjects and methods

SUBJECTS

Ten healthy male volunteers, seven white and three oriental, gave written, informed consent to participate in the investigation. All subjects 
were students or office workers with no history of regular use of hand-held vibrating tools in occupational or leisure activities. All subjects were non-smokers. None of them reported cardiovascular or neurological disorders, connective tissue diseases, injuries to the upper extremities, or a family history of Raynaud's phenomenon. The mean age of the subjects was 31.5 (SD 9.3) years, their mean height was 178 (SD 7.6) $\mathrm{cm}$, and their mean weight was 76 (SD 11.0) kg. Finger dimensions were measured with Vernier callipers to a precision of $0.5 \mathrm{~mm}$. Finger volume and surface area were calculated from that of a cylinder formed from an ellipse based on the dimensions of the proximal interphalangeal joint and the length of the finger. The mean (SD) volume of the middle right finger was $24.7(4.0) \mathrm{cm}^{3}$ and that of the middle left finger was $23.2(3.1) \mathrm{cm}^{3}$. The mean (SD) surface areas were 98.7 (15.9) $\mathrm{cm}^{2}$ and $93.0(12.3) \mathrm{cm}^{2}$ for the middle right and the middle left finger, respectively.

\section{MEASURES OF FINGER CIRCULATION}

Finger blood flow (FBF) and finger systolic blood pressure (FSBP) were measured in the middle fingers of both the right and the left hand. The methods of measuring FBF and FSBP are similar to those reported elsewhere. ${ }^{23}$ Briefly, mercury in silastic strain gauges was placed around the distal phalanx at the base of the nails, and plastic pressure cuffs for air inflation $(2.4 \times 9 \mathrm{~cm})$ were fixed around the proximal phalanges and secured with a Velcro strip. The pressure cuffs and strain gauges were connected to a plethysmograph (Digitmatic DM2000, Medimatic A/S, Copenhagen).

The FBF was measured with a venous occlusion technique: the pressure cuffs were inflated to a pressure of between 40 and $60 \mathrm{~mm}$ $\mathrm{Hg}$ and the rise of volume was detected by means of the strain gauge according to the criteria given by Greenfield et al. ${ }^{8}$ Three to five plethysmographic recordings of FBF were made for each measurement, and the mean value was calculated. The FBF measurements were expressed as $\mathrm{ml} / 100 \mathrm{ml} / \mathrm{min}$.

The FSBP was measured with the technique described by Nielsen et al. ${ }^{9}$ The tips of the middle fingers were squeezed and the pressure cuffs inflated to a suprasystolic pressure of 200 $\mathrm{mm} \mathrm{Hg}$. The pressure in the cuffs was then reduced at about $3 \mathrm{~mm} \mathrm{Hg} / \mathrm{s}$. The FSBP was defined as the cuff pressure at which a volume increase was detected in the distal phalanx by means of the strain gauge.

Brachial systolic and diastolic blood pressures were measured in the upper right arm by an auscultatory technique with a standard rubber cuff $(12 \times 23 \mathrm{~cm})$.

The measures of finger and brachial blood pressures were obtained at the beginning and at the end of each experimental session.

Finger skin temperature (FST) was measured using $\mathrm{k}$ type thermocouples connected to an HVLab thermal aesthesiometer so as to measure temperatures with an accuracy of $\pm 0.2^{\circ} \mathrm{C}$. The thermocouples were taped to the dorsal surface of the medial phalanges of the middle fingers with a porous surgical tape.

The room temperature was measured by a mercury in glass thermometer.

\section{EXPERIMENTAL PROCEDURE}

The experiments were performed in a room with a mean (SD) temperature of $27.8(0.8)^{\circ} \mathrm{C}$. Subjects were requested to avoid caffeine consumption for 2 hours and alcohol for 12 hours before testing.

The subjects lay supine throughout the investigation with the hands resting on wooden platforms alongside the body at about the level of the heart. They wore no clothing above the waist; the torso was covered with a thin sheet.

After a period of acclimatisation of about 15-20 minutes, FBF and FST were measured in the middle fingers of both hands. After the pre-exposure measurements had been obtained, the subjects were asked to apply a downward force of $10 \mathrm{~N}$ with their right hand on a wooden platform that was mounted on an electrodynamic vibrator (VP4, Derritron). Visual feedback for the control of downward force was supplied by an analogue force meter connected to a force cell mounted between the platform and the shaker. All fingers of the right hand were in contact with the wooden platform. The arrangement for controlling contact force and generating vibration has been described elsewhere. ${ }^{10}{ }^{11}$ These previous studies have found no large significant effects of a static force of $10 \mathrm{~N}$ on FBF during or after its application. The force was controlled in this study because it affects the transmission of vibration to the fingers and hand and the deformation of various body tissues caused by vibration.

Sinusoidal vibration was produced in the vertical direction with one of the combinations of frequency and rms magnitude shown in table 1 . The frequencies and unweighted $\mathrm{rms}$ acceleration magnitudes of vibration were chosen so as to produce the same frequency weighted acceleration magnitude $\left(5.5 \mathrm{~m} / \mathrm{s}^{2}\right.$ rms) according to the frequency weighting recommended by ISO 5349. ${ }^{4}$ The duration of exposure to vibration was 15 minutes. This duration of exposure to a weighted rms acceleration of $5.5 \mathrm{~m} / \mathrm{s}^{2}$ gives an 8 hour energy equivalent exposure of $1.0 \mathrm{~m} / \mathrm{s}^{2}$ according to the daily time dependency for hand transmitted vibration assumed in current standards. ${ }^{45}$ The exposure-response relation included in an annex to ISO 5349 predicts that vibration induced white finger (VWF) would occur in $10 \%$ of an exposed population after about 21 years of daily exposure to a weighted acceleration magnitude equivalent to that used in this study. $^{4}$

The measurements of FBF and FST were made in both the exposed (right) and nonexposed (left) middle fingers immediately before exposure to vibration, throughout the period of exposure to vibration, and for 45 minutes after exposure. The measures of finger circulation were obtained at $0.5,1.5,3.5,5.5$, 7.5 , and 15 minutes after the start of vibration. Measures were taken at the same intervals after 
Table 1 Conditions of exposure to static load and vibration used in the study (the frequency weighted root mean square (rms) acceleration of vibration was calculated according to the international standard ISO 5349)

\begin{tabular}{llll}
\hline $\begin{array}{l}\text { Vibration } \\
\text { frequency } \\
(\mathrm{Hz})\end{array}$ & $\begin{array}{l}\text { Unweighted } \\
\text { acceleration } \\
\left(\mathrm{m} / \mathrm{s}^{2}, \text { rms }\right)\end{array}$ & $\begin{array}{l}\text { Frequency weighted } \\
\text { acceleration } \\
\left(\mathrm{m} / \mathrm{s}^{2}, \text { rms }\right)\end{array}$ & $\begin{array}{l}\text { Exposure } \\
\text { duration } \\
\text { (min) }\end{array}$ \\
\hline Static load & 0 & 0 & 15 \\
16 & 5.5 & 5.5 & 15 \\
31.5 & 11 & 5.5 & 15 \\
63 & 22 & 5.5 & 15 \\
125 & 44 & 5.5 & 15 \\
250 & 88 & 5.5 & 15 \\
\hline
\end{tabular}

the end of vibration and then at each 7.5 minute interval during the rest of the recovery period.

A control condition consisted of the same procedure, with the vibration magnitude reduced to zero but the contact force on the wooden surface maintained at $10 \mathrm{~N}$ for 15 minutes.

The exposure (vibration) and control (static load) conditions were presented randomly in six separate experimental sessions with 1-4 days between the exposures. Each experimental session lasted about 1.5 hours.

The study was approved by the Human Experimentation Safety and Ethics Committee of the Institute of Sound and Vibration Research at the University of Southampton (UK).

\section{STATISTICAL METHODS}

Data analysis was performed with the software packages BMDP/Dynamic (release 7.0) and Stata (version 6.0). The data were summarised with the mean as a measure of central tendency and the SD, the SEM, or the $95 \%$ confidence interval $(95 \% \mathrm{CI})$ as measures of dispersion. The difference between two means was tested by a paired or unpaired Student $t$ test when appropriate.

As the present study entailed serial measurements of the same variables on the same man at several points in time, a sample size of 10 men was estimated to be adequate for this type of experimental design. ${ }^{12}$ Repeated measures analysis of variance (ANOVA) was used to test the hypothesis of no difference in the vascular responses under different exposure conditions (treatments). When the treatment by time interaction term in ANOVA was found to be significant $(p<0.05)$, a separate analysis of the results within treatments was made. To control for the effect of covariates on the response variables, repeated measures analysis of covariance (ANCOVA) was also used. When the assumption of compound symmetry for the orthogonal polynomial components of repeated measures was violated, a conservative test of the repeated measures factor was used by reducing the degrees of freedom of the $F$ ratio (GreenhouseGeisser method). ${ }^{13}$ The Bonferroni 95\% CIs for pairwise mean comparisons of the response by time were used when the probability value for the $F$ test of repeated measures ANOVA was $\mathrm{p}<0.05$ (two sided).

The relation between continuous variables with repeated measures was assessed by the generalised estimating equations (GEE) ap- proach to repeated measures data sets to account for the correlation within a subject. ${ }^{14}$

The relation of the maximum reduction in FBF to vibration frequency was assessed by the GEE method in association with the technique of fractional polynomials to check for the linearity of the relation. ${ }^{15}$ When the relation was non-linear, the appropriate fractional polynomial transformation was applied to the predictor variable to obtain the best fitting model.

\section{Results}

The air temperature in the laboratory did not show significant variations across the six experimental sessions (range of mean values $27.6-28.1^{\circ} \mathrm{C}$ ). Brachial systolic and diastolic arterial pressures measured before exposure did not change significantly within subjects across sessions (range of values across subjects 110/70-140/85 $\mathrm{mm} \mathrm{Hg}$ ). There were no significant differences within subjects for FBF, FSBP, and FST measured before exposures to static load and vibration in either the exposed or the unexposed finger. The pre-exposure measures of digital circulation showed no differences between the middle right and the middle left finger within any session. No differences were found for finger or brachial arterial blood pressures measured at the beginning and the end of the six sessions.

In pre-exposure conditions, analysis of repeated measures by the GEE method showed that FBF was positively related to FST $(p<0.001)$ and finger volume $(p<0.05)$ in both the middle right and the middle left finger. The FSTs in both fingers were related to room temperature $(p<0.01)$, but not to finger surface areas $(p>0.5)$. In neither finger was there a significant relation between FSBP and FBF or between FSBP and FST. Age was not related to the pre-exposure measurements of digital circulation.

\section{FINGER SKIN TEMPERATURE}

Before exposure, the mean (SD) values of FST varied from $34.0(1.4)$ to $34.6(1.1)^{\circ} \mathrm{C}$ in the right (exposed) finger and from 33.5 (2.0) to $34.4(1.7)^{\circ} \mathrm{C}$ in the left (unexposed) finger. While controlling for age, finger surface area, and room temperature, repeated measures ANCOVA showed no differences in FST between the six exposure conditions for either finger during exposure (to vibration or static load) or during the recovery period (results not shown).

FINGER BLOOD FLOW

Figure 1 shows the mean values of FBF measured in both the middle right (exposed) and the middle left (unexposed) finger before, during, and after exposures to static load only and vibration with different frequencies but with the same frequency weighted acceleration magnitude $\left(5.5 \mathrm{~m} / \mathrm{s}^{2} \mathrm{rms}\right)$. When data analysis was performed over the full period (preexposure, exposure, and recovery) of the six experimental sessions, repeated measures ANCOVA showed a significant treatment by time interaction for both fingers $(\mathrm{p}<0.001)$. Thus, 


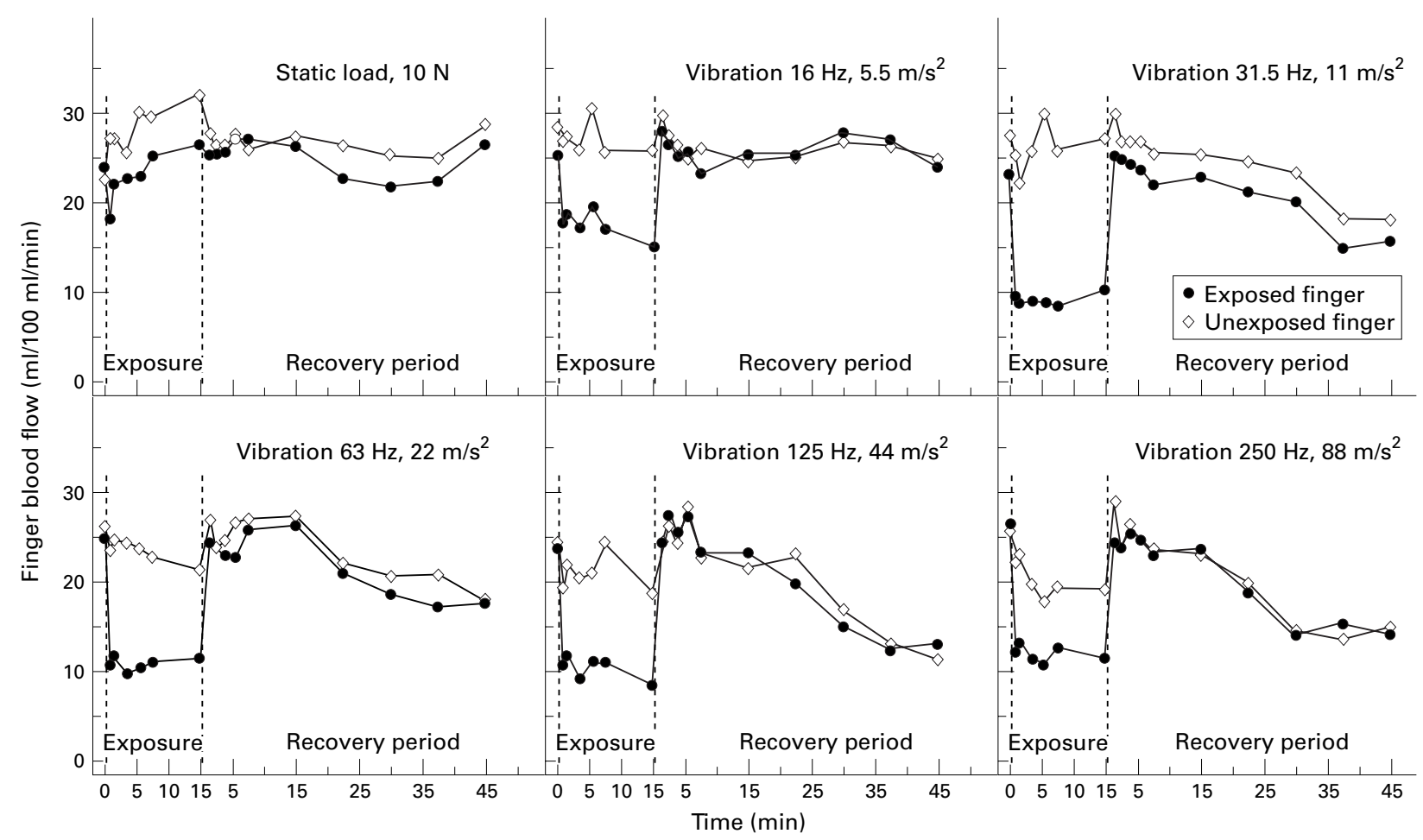

Figure 1 Mean values of finger blood flow measured in 10 healthy men before, during, and after 15 minutes of exposure to static load (contact force 10 $N)$ or vibration with different combinations of frequencies $(\mathrm{Hz})$ and unweighted acceleration magnitudes $\left(\mathrm{m} / \mathrm{s}^{2} \mathrm{rms}\right)$ but with the same frequency weighted acceleration $\left(5.5 \mathrm{~m} / \mathrm{s}^{2} \mathrm{rms}\right.$ ) according to the frequency weighting recommended by the international standard ISO 5349 (table 1).

the changes of FBF were examined within each exposure condition. Tables 2 and 3 report the mean (SEM) values for FBF in the exposed and unexposed fingers throughout the various experimental sessions, respectively, as well as the mean $(95 \% \mathrm{CI})$ values for the percentage changes in FBF compared with the measures before exposure.

Exposure to only static load did not cause significant changes in the FBF of either finger. Acute exposure to vibration of any frequency provoked a significant reduction of FBF in the right (vibrated) finger $(\mathrm{p}<0.001)$. A multiple comparison test (Bonferroni method) showed that at each measurement time during the exposure period, there was a significant decrease in the FBF of the vibrated finger for vibration frequencies of $31.5-250 \mathrm{~Hz}$ when compared with the pre-exposure measures (table 2). The decrease in FBF during exposure to vibration with a frequency of $16 \mathrm{~Hz}$ was significant only at the 15 th minute of the exposure period.

Over the whole experimental period, vibration with frequencies of $31.5-250 \mathrm{~Hz}$ induced significant changes in FBF in the left (nonvibrated) finger (table 3). Exposure to a vibration frequency of $16 \mathrm{~Hz}$ did not cause any significant change in the blood flow of the non-vibrated finger.

When data analysis was limited to the FBF measured during the exposure period, the treatment by time interaction term was not significant for either finger $(\mathrm{p}>0.25)$, and repeated measures ANCOVA showed that the changes in the FBF of both the vibrated and the non-vibrated finger differed significantly between the six experimental conditions. Over the whole exposure period, the percentage reduction of FBF in the right (vibrated) finger was significantly greater during exposures to vibration with frequencies of $31.5 \mathrm{~Hz}$ (mean: $-51.6 \%$; 95\% CI: -18.1 to $-85.2 \%), 63 \mathrm{~Hz}$ (mean: $-50.1 \%$; 95\% CI: -16.6 to $-83.6 \%$ ), $125 \mathrm{~Hz}$ (mean: $-51.3 \%$; 95\% CI: -17.8 to $-84.8 \%$ ), and $250 \mathrm{~Hz}$ (mean: $-50.2 \%$; $95 \%$ CI: -16.7 to $-83.8 \%$ ) than during exposure to static load only. No difference in the changes of FBF was found between exposures to static load and vibration with a frequency of $16 \mathrm{~Hz}$. No significant differences in the reduction of FBF were found between exposures to vibration at frequencies of $31.5-250 \mathrm{~Hz}$.

Throughout the exposure period, the percentage reduction of FBF in the left (nonvibrated) finger was significantly greater during exposures to vibration with frequencies of 63 $\mathrm{Hz}$ (mean: $-37.2 \%$; $95 \% \mathrm{CI}:-7.8$ to $-66.7 \%$ ), $125 \mathrm{~Hz}$ (mean: $-38.4 \%$; 95\% CI: -8.9 to $-67.8 \%$ ), and $250 \mathrm{~Hz}$ (mean: $-44.5 \%$; 95\% CI: -15.1 to $-73.9 \%$ ) than during exposure to static load only. In the non-vibrated finger, there were no differences in FBF between exposures to static load and vibration frequencies of 16 or $31.5 \mathrm{~Hz}$, or between exposures to vibration frequencies of $63-250 \mathrm{~Hz}$.

At each measurement time during exposure to vibration with any frequency, the reduction of FBF was stronger in the vibrated finger than in the non-vibrated finger $(0.001<p<0.05)$. Significant differences in the FBF between the right (exposed) and the left (unexposed) finger were also found at the 30 second and $1.5 \mathrm{~min}$ utes during exposure of the right hand to static load only $(\mathrm{p}<0.05)$. This change seems to have 


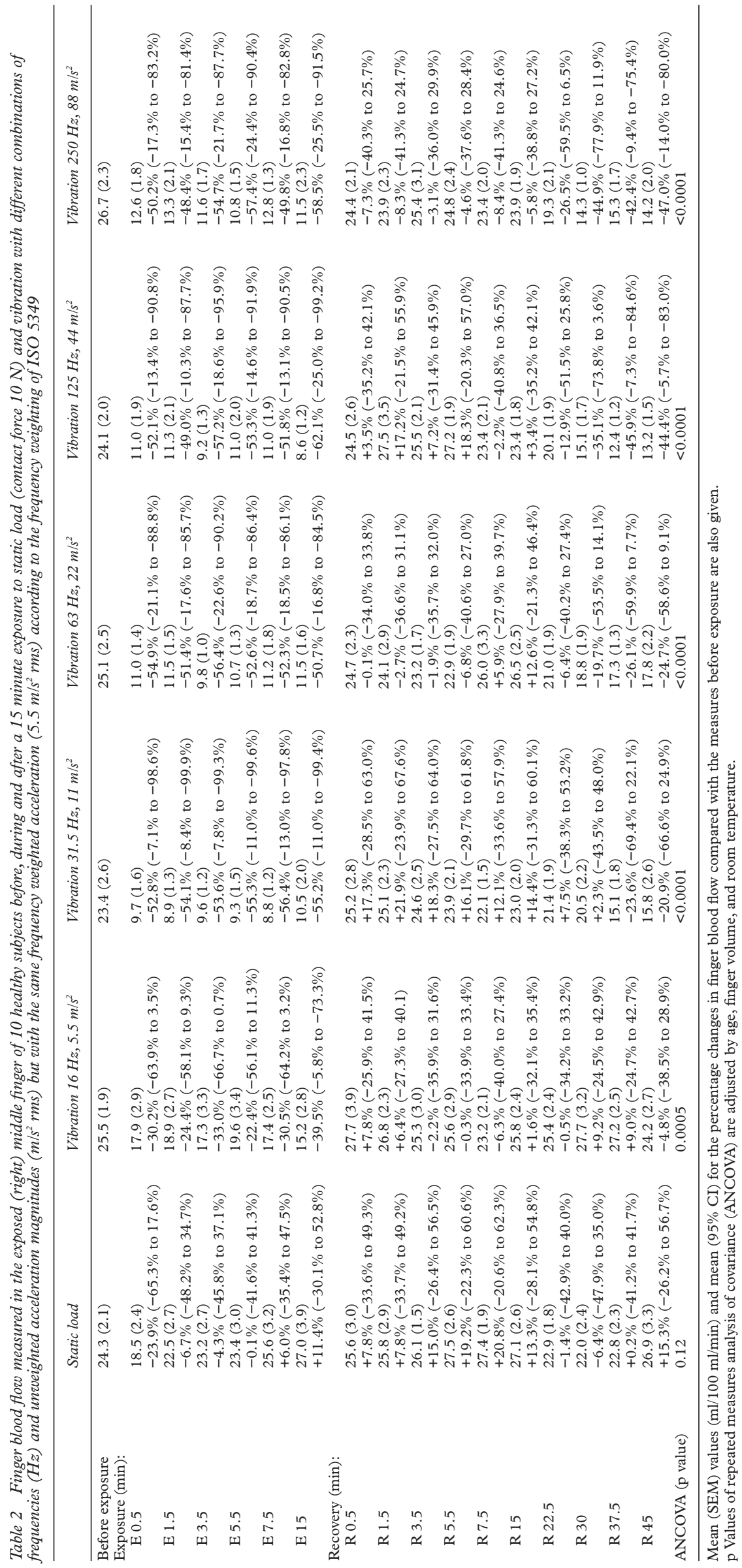




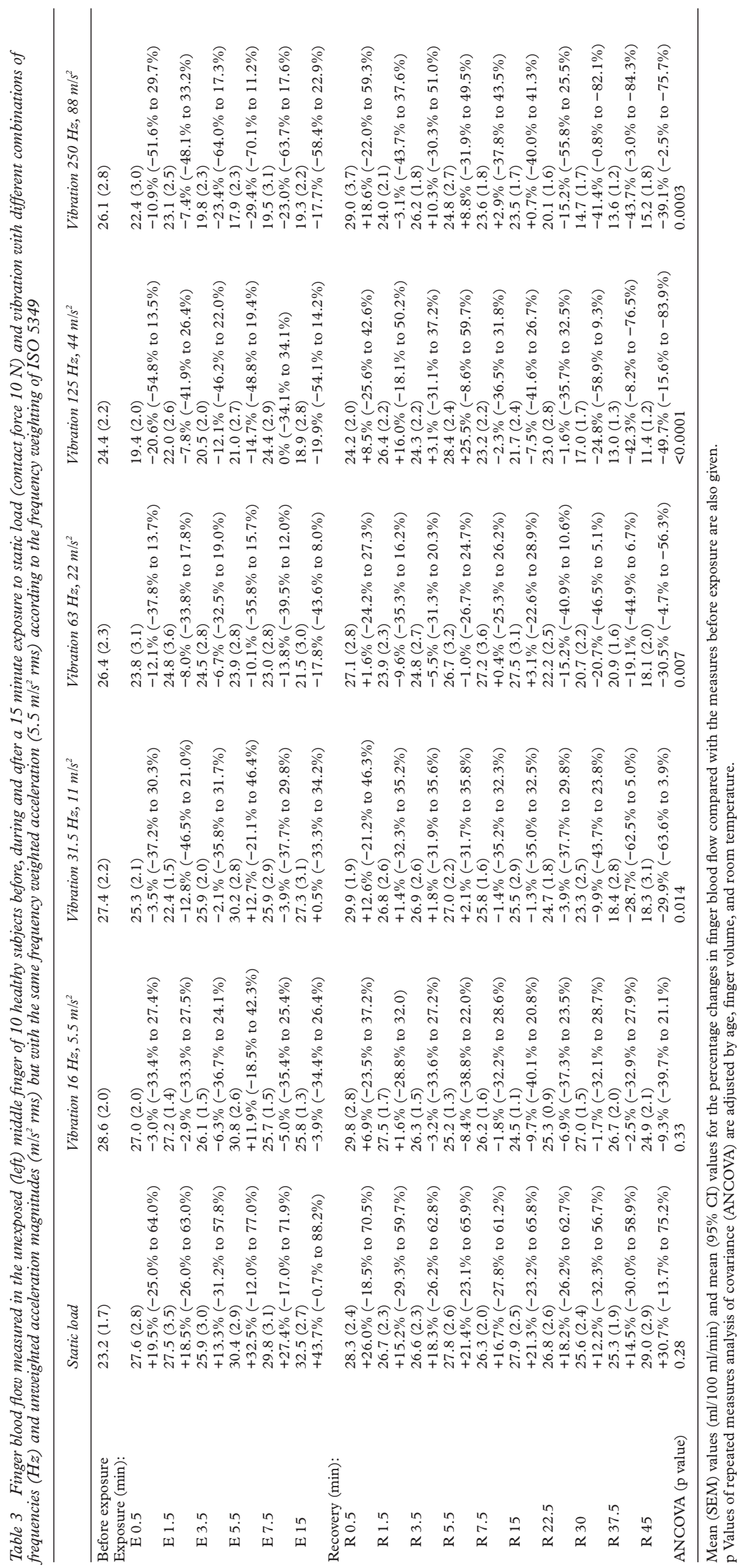


arisen from a reduction in $\mathrm{FBF}$ in the exposed finger and an increase in FBF in the unexposed finger.

Immediately after vibration stopped, there was an increase in the FBF of the right (vibrated) finger. This vasodilation was found after exposure to vibration at each frequency. On average, the immediate increase in $\mathrm{FBF}$ was significant when compared with the last measure of FBF taken at the 15 th minute during exposure to vibration: $+47.3 \%$ (95\% CI: 13.6 to $81.0 \%$ ) at $16 \mathrm{~Hz},+72.5 \%$ (95\% CI: 26.7 to $118 \%)$ at $31.5 \mathrm{~Hz},+50.5 \%$ (95\% CI: 16.7 to $84.4 \%)$ at $63 \mathrm{~Hz},+65.6 \%$ (95\% CI: 27.0 to $104 \%$ ) at $125 \mathrm{~Hz}$, and +51.2\% (95\% CI: 18.2 to $84.2 \%$ ) at $250 \mathrm{~Hz}$. There was no significant difference in the degree of vasodilation between the various vibration frequencies. In the left (non-vibrated) finger, a marginally significant increase in FBF occurred only after the end of exposure to vibration with a frequency of $250 \mathrm{~Hz}$ ( $+36.4 \%$; 95\% CI: 0.5 to $72.5 \%)$.

During the recovery period, a decrease in FBF was found in both the vibrated and the non-vibrated finger, about 30 minutes after the end of exposure to vibration with frequencies of 31.5-250 Hz. When compared with the preexposure measures, the reduction of $\mathrm{FBF}$ in both fingers was significant only after exposure to vibration frequencies of 125 and $250 \mathrm{~Hz}$. During recovery, there was no difference in the degree of vasoconstriction between the right (exposed) and the left (unexposed) finger. The Bonferroni test showed that the decrease in $\mathrm{FBF}$ in either finger from 30 to 45 minutes during the recovery period was greater after exposure to vibration frequencies of either 125 or $250 \mathrm{~Hz}$ than after exposure to vibration with a frequency of $16 \mathrm{~Hz}$ or with the static load $(p<0.05)$. Over this period, there were no differences between FBF after exposures to 31.5 or $63 \mathrm{~Hz}$ and $\mathrm{FBF}$ after exposure to any other condition (static, 16, 125, or $250 \mathrm{~Hz}$ ).

\section{Discussion}

FINGER CIRCULATION DURING EXPOSURE TO VIBRATION

Acute exposures to vibration of frequencies in the range $16-250 \mathrm{~Hz}$ caused a reduction in the FBF of the vibrated finger which was significant when compared with pre-exposure measures. All vibration frequencies used in this study provoked a prompt vasoconstriction in the vibrated finger. This has been found in other experimental studies of the vascular effects of acute hand transmitted vibration and suggests that the immediate reaction of the digital vessels to vibration is mediated by a neurogenic reflex mechanism. ${ }^{1011} 1617$ A similar pathophysiological mechanism is likely to have operated in the left (non-vibrated) finger, which showed a reduction in FBF during acute exposure of the right hand to the higher vibration frequencies used in this study (63-250 $\mathrm{Hz}$ ). A decrease in the FBF of the contralateral finger to vibration has been reported previously. ${ }^{17}{ }^{18}$ It has been hypothesised that the vasoconstrictor response in the non-vibrated finger is the result of a central sympathetic vasomotor reflex, possibly elicited by the activation of the subcutaneous pacinian corpuscles which are strongly sensitive to mechanical stimuli at these higher frequencies. ${ }^{16} \mathrm{~A}$ central reflex would be consistent with the finding that a reduction in blood flow can occur even in some areas of the legs during exposure of the hands to vibration. ${ }^{19}$ During exposure to vibration, however, vasoconstriction in the vibrated finger was significantly greater than that in the non-vibrated finger. This suggests that as well as a central sympathetic reflex mechanism, local vasoconstrictor factors may also be active in the hand which is in contact with the source of vibration. ${ }^{211} 17$

FINGER CIRCULATION AFTER EXPOSURE TO VIBRATION

In this study, the end of exposure to vibration was followed by an immediate increase in FBF with complete recovery of the resting values of FBF in both fingers. The degree of digital vasodilation was greater in the vibrated finger than in the non-vibrated finger. This vasodilation after exposure has been found in other experimental investigations and has been ascribed to several factors such as a release of local vasodilatory substances, a vibration induced impairment of the muscular autoregulatory function in the terminal arterioles, or a reduction of the sympathetic vasomotor tone due to a diminished discharge from the afferent skin mechanoreceptors no longer excited by the vibration stimulus. ${ }^{3112021}$

After effects of vibration represented by an excessive vasoconstrictive reaction occurring from 15 minutes to 4 hours after the end of a vibration stimulation, have been found in blood vessel specimens of experimental animals and in human fingers. ${ }^{6}{ }^{19} 22$ The present study confirms the existence of persisting after effects of vibration: a progressive reduction of FBF was found in both fingers during the second half of the recovery periods after exposures to vibration with frequencies of $31.5-250 \mathrm{~Hz}$. It has been suggested that these after-effects are the result of a hyperreactivity of the sympathetic nervous system induced by vibration because they are found in both the vibrated and the non-vibrated fingers. ${ }^{22}$ Nevertheless, a role for other factors, such as circulating vasopressor agents, can not be excluded as hyperresponsiveness to noradrenaline (norepinephrine) up to 4 hours after the end of vibration stimulation has been found in denervated and isolated arteries of dogs. ${ }^{6}$ Moreover, this hyperresponse to noradrenaline was found to increase with the increase of the frequency of vibration up to 30-50 Hz, whereas no hyperresponse was induced by vibration $<10 \mathrm{~Hz}$. These findings seem to be consistent with the results of this study in which the vasoconstrictor after effects of vibration during the recovery periods were found to be dependent on the frequency of vibration (top and bottom right graphs in fig 2).

CONSIDERATIONS ON THE FREQUENCY WEIGHTING OF VIBRATION

Previous laboratory investigations have studied the acute effects of the frequency of vibration 


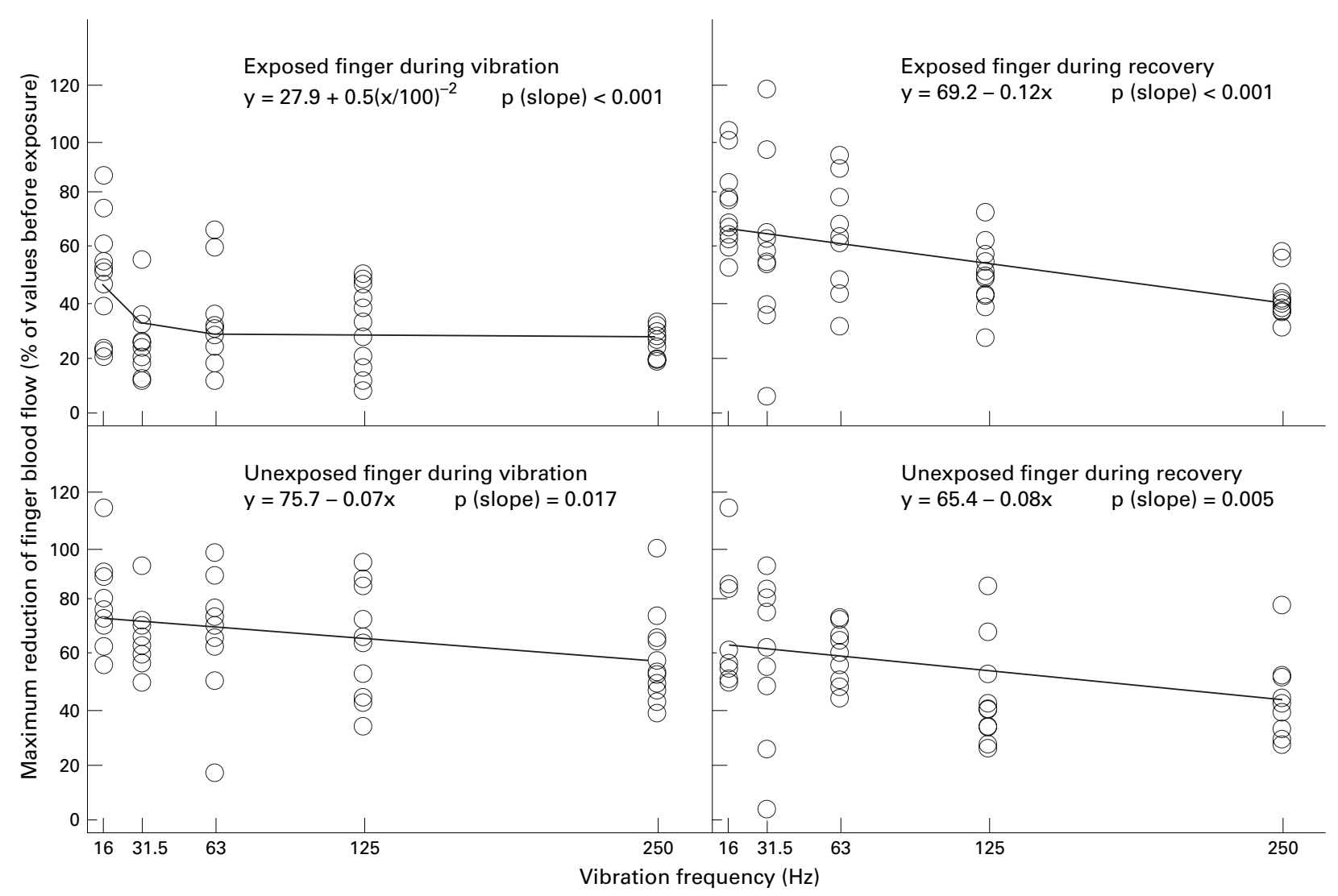

Figure 2 Effects of vibration frequency on the maximum reduction of finger blood flow (expressed as a percentage of the pre-exposure values) during and 45 minutes after exposure to vibration with a frequency weighted acceleration of $5.5 \mathrm{~m} / \mathrm{s}^{2} \mathrm{rms}$. The relations were modelled by the generalised estimating equations (GEE) approach to repeated measures to account for the correlation within a subject. A fractional polynomial transformation was applied to the predictor variable in the top left graph to obtain the best fitting model.

with vibration stimuli with either acceleration of constant magnitudes or displacement of varying amplitudes. ${ }^{716} 172324$ To our knowledge, this is the first experimental study which has been designed to ascertain whether the frequency weighting curve included in current standards for hand transmitted vibration is useful for predicting the acute vascular effects on the hands of subjects exposed to vibration. ${ }^{45}$ Previous studies have investigated the acute vascular response to vibration with frequencies of $16-1000 \mathrm{~Hz}$ in experimental animals, normal people, or workers affected with vibration induced white finger. ${ }^{6} 711$ 16-18 2324 However, the findings have not been unequivocal for the vascular effects of the frequency of vibration. Some authors have reported that vibration frequencies of 31.5-63 and $250-500 \mathrm{~Hz}$ cause a stronger reduction of FBF than other frequencies. ${ }^{72}$ Other researchers found that vibration frequencies in the range $80-125 \mathrm{~Hz}$ were more effective in inducing digital vasospasm than either lower or higher frequencies. ${ }^{163}$ In this study, the extent of the acute response of finger circulation to hand transmitted vibration was also found to be dependent on the frequency of the vibration applied to the whole hand. When the vibration acceleration magnitude was weighted according to the frequency weighting in ISO 5349, vibration with frequencies of $31.5-250 \mathrm{~Hz}$ and a weighted $\mathrm{rms}$ acceleration of $5.5 \mathrm{~m} / \mathrm{s}^{2}$ induced more powerful vasoconstrictor effects in the vessels of the vibrated finger than a vibration with a frequency of $16 \mathrm{~Hz}$ at the same weighted rms acceleration magnitude. In the frequency range $31.5-250 \mathrm{~Hz}$, vibration with identical frequency weighted acceleration magnitudes caused a similar degree of vasoconstriction in the vibrated finger. These effects are evident in figure 2 (top left graph), which shows a non-linear relation between the frequency of vibration and the maximum reduction of FBF in the vibrated finger during exposure to vibration. When the measures of FBF obtained during $16 \mathrm{~Hz}$ exposure were excluded from data analysis, there was no significant trend for the decrease in FBF during exposure to vibration at frequencies of $31.5-250 \mathrm{~Hz}$ (slope $-0.013, \mathrm{p}=0.59$ ). A different exposure-effect relation was found in the non-vibrated finger during exposure to vibration (bottom left graph in fig 2): the FBF in the unexposed finger was found to reduce roughly linearly with an increase in vibration frequency $(p=0.017)$. Overall, these findings seem to indicate that the frequency weighting in ISO 5349 does not reflect the pattern of acute response of the digital vessels to vibration; the ISO weighting tends to overestimate the effects of vibration at the lower frequencies, around 16 $\mathrm{Hz}^{4}$

The acute vascular responses during and after exposure to vibration may not be separate independent effects of vibration frequency, magnitude, and duration: there may be complex interactions between the effects of these variables. For example, the effect of vibration 
magnitude may, in general, be non-linear and differ according to the frequency and duration of exposure to vibration. Current frequency weightings and duration weightings assume that the effects of hand transmitted vibration are independent functions of vibration magnitude. Although the interpretation of the results of the present study in the context of standardisation also makes this simple assumption, it is recognised that further research may be expected to show that the vascular responses to hand transmitted vibration are more complex.

\section{Conclusions}

During exposure to vibration there is a reduction in finger blood flow in both vibrated and non-vibrated fingers. Immediately after exposure to vibration there is vasodilation, followed about 30 minutes later by a progressive reduction in finger blood flow in both vibrated and non-vibrated fingers. This study found that the effects are dependent on the frequency of vibration. With the same frequency weighted magnitude of vibration at all frequencies, only a small response of the digital circulation was elicited at $16 \mathrm{~Hz}$ compared with the response to frequencies of $31.5-250 \mathrm{~Hz}$. Vasoconstriction occurring about 30 minutes after the end of exposure to vibration increased with increasing vibration frequency of $16-250 \mathrm{~Hz}$. The results suggest that the frequency weighting given in ISO 5349 overestimates the acute effects of vibration on the digital circulation at frequencies around $16 \mathrm{~Hz}$.

This research was supported by the European Commission under the BIOMED 2 concerted action BMH4-CT98-3251 (Vibration Injury Network).

1 Griffin MJ. Handbook of human vibration. London: Academic Press, 1990.

2 Bovenzi M, Lindsell CJ, Griffin MJ. Duration of acute exposures to vibration and finger circulation. Scand $\mathcal{F}$ Work Environ Health 1998;24:130-7.

3 Bovenzi M, Lindsell CJ, Griffin MJ. Magnitude of acute exposures to vibration and finger circulation. Scand $\mathcal{F}$ Work Environ Health 1999;25:278-84.
4 International Organization for Standardization. Mechanical vibration: guidelines for the measurement and the assessment of human exposure to hand transmitted vibration. Geneva: ISO, 1986:5349.

5 British Standards Institution. Measurement and evaluation of human exposure to vibration transmitted to the hand. London: BSI, 1987:6842.

6 Azuma T, Ohhashi T, Sakaguchi K. Vibration-induced hyperresponsiveness of arterial smooth muscle to adrenaline with special reference to Raynaud's phenomenon in vibration disease. Cardiovasc Res 1978;12:758-64.

7 Furuta M, Sakakibara H, Miyao M, et al. Effect of vibration frequency on finger blood flow. Int Arch Occup Environ Health 1991;63:221-4.

8 Greenfield ADM, Whitney RJ, Mowbray JF. Methods for the investigation of peripheral blood flow. Br Med Bull 1963;19:101-9.

9 Nielsen SL, Bell G, Lassen NA. Strain gauge studies of distal blood pressure in normal subjects and in patients with peripheral arterial disease. Analysis of normal variation and reproducibility and comparison to intraartierial measurements. Scand f Clin Lab Invest 1973;31(suppl 128):103-9.

10 Bovenzi M, Griffin MJ, Ruffell CM. Acute effects of vibration on digital circulatory function in healthy men. Occup Environ Med 1995;52:834-41.

11 Bovenzi M, Griffin MJ. Haemodynamic changes in ipsilateral and contralateral fingers caused by acute ipsilateral and contralateral fingers caused by acute Med 1997;54:566-76.

12 Crowder MJ, Hand DJ. Analysis of repeated measures. London: Chapman and Hall, 1990

13 Greenhouse SW, Geisser S. On methods in the analysis of profile data. Psychometrika 1959;24:95-111.

14 Diggle PJ, Liang KY, Zeger SL. Analysis of longitudinal data. Oxford: Oxford University Press, 1994. (Oxford Statistical Science Series No 13.)

15 Royston P, Altman DG. Regression using fractional polynomials of continuous covariates: parsimonious parametric modelling (with discussion). Appl Stat 1994;43:429-67.

16 Hyvärinen J, Pyykkö I, Sundberg S. Vibration frequencies and amplitudes in the etiology of traumatic vasospastic disease. Lancet 1973;i:791-4.

17 Kent PJ, Williams G, Kester RC. Altered sensitivity of digital blood flow to acute vibration in patients with vasospastic disease. F Biomed Eng 1991;13:269-71.

18 Färkillä M, Pyykkö I. Blood flow in the contralateral hand during vibration and hand grip contractions of lumber jacks. Scand $\mathcal{F}$ Work Environ Health 1979;5:368-74.

19 Egan CE, Espie BH, McGrann S, et al. Acute effects of vibration on peripheral blood flow in healthy subjects. Occup Environ Med 1996;53:663-9.

20 Greenstein D, Kester D. Acute vibration: its effect on digital blood flow by central and local mechanisms. Proceedings of the Institute of Mechanical Engineers (Part H) 1992;206:105-

21 Olsen N, Petring OU, Rossing N. Transitory postural vasomotor dysfunction in the finger after short term hand vibration. Br f Ind Med 1989;46:575-81.

22 Olsen N. Vibration aftereffects on vasoconstrictor response to cold in the normal finger. Eur $\mathcal{f}$ Appl Physiol to cold in the

23 Welsh CL. The effect of vibration on digital blood flow. $\mathrm{BrF}$ Surg 1980;67:708-10.

24 Nohara S, Okamoto K, Okada A. Peripheral circulatory and nervous response to various frequencies of local vibration exposure. Scand $\mathcal{F}$ Work Environ Health 1986;12:382-4.

\section{Correspondence and editorials}

Occupational and Environmental Medicine welcomes correspondence relating to any of the material appearing in the journal. Results from preliminary or small scale studies may also be published in the correspondence column if this seems appropriate. Letters should be not more than 500 words in length and contain a minimum of references. Tables and figures should be kept to an absolute minimum. Letters are accepted on the understanding that they be subject to editorial revision and shortening.

The journal also publishes editorials which are normally specially commissioned. The Editor welcomes suggestions regarding suitable topics; those wishing to submit an editorial, however, should do so only after discussion with the Editor. 